This article is licensed under the Creative Commons Attribution-NonCommercial 4.0 International License (CC BY-NC) (http://www.karger.com/Services/OpenAccessLicense). Usage and distribution for commercial purposes requires written permission.

\title{
Linked Color Imaging Highlights Flat Early Gastric Cancer
}

\author{
Kimitoshi Kubo ${ }^{a}$ Noriko Kimura ${ }^{b}$ Soichiro Matsuda ${ }^{a}$ Momoko Tsuda $^{a}$ \\ Mototsugu Kato ${ }^{a}$ \\ aDepartment of Gastroenterology, National Hospital Organization Hakodate National \\ Hospital, Hakodate, Japan; 'bepartment of Pathology, National Hospital Organization \\ Hakodate National Hospital, Hakodate, Japan
}

\section{Keywords}

Endoscopy · Linked color imaging · Early gastric carcinoma $\cdot$ Detection

\begin{abstract}
While linked color imaging ( $\mathrm{LCl}$ ) may allow flat early gastric cancer to be detected early, the endoscopic and pathological features of lesions detected by $\mathrm{LCl}$ remain poorly described. Screening esophagogastroduodenoscopy performed on a 68-year-old woman revealed a yellowish, flat lesion shown to be reddish in its central area, located in the anterior wall of the gastric lower body on white light imaging (WLI). On LCl, the lesion was highlighted as an orangish, flat lesion shown to be purple-colored in its central area, surrounded by lavendercolored tissue. Endoscopic submucosal dissection performed led to the patient being diagnosed with tubular adenocarcinoma, well-differentiated type (tub1), pT1a (M). This case suggests that $\mathrm{LCl}$ may prove more useful than WLI for the detection of flat early gastric cancer lesions.

(C) 2019 The Author(s)

Published by S. Karger AG, Basel
\end{abstract}




\section{Case Reports in Gastroenterology}

Case Rep Gastroenterol 2019;13:532-538

DOI: $10.1159 / 000504957$

(C) 2019 The Author(s). Published by S. Karger AG, Basel www.karger.com/crg

Kubo et al.: Linked Color Imaging Highlights Flat Early Gastric Cancer

\section{Introduction}

Flat early gastric cancer is difficult to detect early with white light imaging (WLI) because of its invisibility $[1,2]$. Additionally, it tends to be more difficult even for well-trained endoscopists to detect in H. pylori-associated atrophic gastritis, with the result that early gastric cancers are frequently missed on WLI [3]. Linked color imaging (LCI) (FUJIFILM Co., Ltd., Tokyo, Japan) has recently been developed for advanced image-enhanced endoscopy. LCI emphasizes slight differences in color between mucosal surface structures and vessels, which may reflect differences in reflectance at short wavelengths from the superficial layer of the mucosa, thus making them easily recognizable [4]. While LCI is shown to allow flat early gastric cancer lesions to be highlighted and detected as such, currently, the endoscopic and pathological features of LCI-detected lesions remain poorly described. We herein report a case of flat early gastric cancer in which LCI proved useful for its early detection, as well as the endoscopic and pathological features of a lesion detected by LCI.

\section{Case Report/Case Presentation}

\section{Case Presentation}

Screening esophagogastroduodenoscopy (EGD) performed on a 68-year-old woman revealed a yellowish, flat lesion shown to be reddish in its central area, located in the anterior wall of the gastric lower body on white-light imaging (WLI) (Fig. 1a). This reddishness was similar in color to that in the surrounding mucosa and was difficult to recognize as a neoplastic lesion. Using LCI, the lesion was highlighted as an orangish, flat lesion shown to be purplecolored in its central area, surrounded by lavender-colored tissue (Fig. 1b). On blue laser imaging (BLI), the lesion was depicted as a brownish, well-circumscribed flat lesion (Fig. 1c). Furthermore, an irregular microvascular pattern was shown to be present within the demarcation line on magnifying BLI (Fig. 1d). Based on these findings, the lesion was diagnosed as early gastric cancer. An EGD biopsy revealed the lesion to be adenoma. The patient was shown to be positive for the rapid urea test, suggesting the presence of H. pylori-associated atrophic gastritis.

Endoscopic submucosal dissection (ESD) was performed on the suspected well-differentiated tubular adenocarcinoma for biopsy and endoscopic diagnosis. Macroscopically, the resected specimen was a $40 \times 32 \mathrm{~mm}$ lesion with a negative margin (Fig. 2a). A histological examination showed the lesion to be well-differentiated type (tub1) tubular adenocarcinoma (Fig. 2b) surrounded by intestinal metaplasia (Fig. 2c). The gastric lesion in the patient was therefore diagnosed as adenocarcinoma, type 0 -IIb, measuring $7 \times 5 \mathrm{~mm}$, tub1, pT1a (M). Each of these sections was shown to have negative margins. H. pylori was successfully eradicated after ESD. An EGD examination revealed no signs of recurrence for 3 years.

We evaluated the color contrasts between the redness part of the lesion (red squares), the discolored part of the lesion (yellow squares), and the surrounding mucosa (green squares) at five sampling points $(10 \times 10$ pixels) (Fig. 3a, b). The color differences were calculated by using the Commission International de l'Eclairage (CIE) $1976 \mathrm{~L}^{*} \mathrm{a}^{*} \mathrm{~b}^{*}$ color space [5]. The $L^{*} a^{*} b^{*}$ value $\left(L^{*}\right.$ defined as lightness, $a^{*}$ as the red-green component, and $b^{*}$ as the yellow-blue component) was measured by using Adobe Photoshop CS2 (Adobe Systems, San 
Jose, CA, USA) to estimate the color differences present ( $\Delta \mathrm{E}$ ). The mean (standard deviation) color difference between the yellowish part of the lesion and the surrounding mucosa was significantly larger with LCI than with WLI (17.5 [4.4] vs. 8.6 [2.5]; $p<0.01$ ), while no significant difference was found between the reddish and the yellowish part of the lesion (Table 1).

\section{Discussion/Conclusion}

Our case has two important clinical implications. First, LCI is useful for the detection of flat early gastric cancer. However, while flat early gastric cancer is highlighted and detected as such by LCI, the endoscopic and pathological features of LCI-detected lesions remain poorly described in the literature.

Flat early gastric cancer is difficult to detect with WLI in H. pylori-associated atrophic gastritis [1-3]. To date, LCI has been reported to be useful for the diagnosis of $H$. pylori infection [6], detection of intestinal metaplasia [7], improvement of endoscopic diagnosis accuracy [8], and detection or improvement of visibility of early gastric cancer [9-15]. Very recently, Fukuda et al. [9] reported that LCI can be used to enhance recognition of early gastric cancer by providing high color contrast to the surrounding gastric intestinal metaplasia. In the present case, WLI depicted the reddish part of the lesion as being similar in color to the surrounding mucosa and did not readily allow the neoplastic lesion to be recognized, while, in contrast, LCI proved helpful in highlighting the color contrast between the yellowish part of the lesion and the surrounding intestinal metaplasia. To the best of our knowledge, this is the first report describing the detection of flat early gastric cancer through high color contrast provided by LCI.

The second implication of our case is that the color difference between the yellowish part of the lesion and the surrounding mucosa was significantly larger with LCI than with WLI. The CIE $1976 \mathrm{~L}^{*} \mathrm{a}^{*} \mathrm{~b}^{*}$ color space was used to assess the color differences objectively [5]. Color differences between early gastric cancer lesions and their surrounding mucosa $[11,13,15]$ have been reported to be significantly larger with LCI than with WLI, similarly to that in our case, while no significant color difference was found in our study between the reddish and the yellowish part of the lesion. Thus, for detection of any suspected early gastric cancer lesion likely to be difficult to detect with WLI, emphasizing the color difference between the lesion and the surrounding mucosa with LCI may prove helpful.

In conclusion, LCI may prove useful for the detection of flat early gastric cancer and may be worth incorporating into upper gastrointestinal screening.

\section{Statement of Ethics}

Written informed consent was obtained from the patient for publication of this case report and any accompanying images. 


\section{Case Reports in Gastroenterology}

Case Rep Gastroenterol 2019;13:532-538

DOI: $10.1159 / 00050495$

(C) 2019 The Author(s). Published by S. Karger AG, Base www.karger.com/crg

Kubo et al.: Linked Color Imaging Highlights Flat Early Gastric Cancer

\section{Disclosure Statement}

The authors have no conflicts of interest to disclose in association with this study.

\section{Funding Sources}

No funding was obtained for this study.

\section{Author Contributions}

K.K., N.K., S.M., M.T., and M.K. carried out and confirmed the diagnosis, provided the details of the case, and contributed to the design of the report. K.K. and M.K. drafted the manuscript. All authors have read and approved the final version of the manuscript.

\section{References}

1 Misumi A, Misumi K, Murakami A, Harada K, Honmyo U, Akagi M. Endoscopic diagnosis of minute, small, and flat early gastric cancers. Endoscopy. 1989 Jul;21(4):159-64.

2 Honmyo U, Misumi A, Murakami A, Mizumoto S, Yoshinaka I, Maeda M, et al. Mechanisms producing color change in flat early gastric cancers. Endoscopy. 1997 Jun;29(5):366-71.

3 Raftopoulos SC, Segarajasingam DS, Burke V, Ee HC, Yusoff IF. A cohort study of missed and new cancers after esophagogastroduodenoscopy. Am J Gastroenterol. 2010 Jun;105(6):1292-7.

4 Osawa H, Miura Y, Takezawa T, Ino Y, Khurelbaatar T, Sagara Y, et al. Linked color imaging and blue laser imaging for upper gastrointestinal screening. Clin Endosc. 2018 Nov;51(6):513-26.

5 Commission International de l'Eclairage. Colorimetry, 3rd Edition. Publication CIE 15: 2004.

6 Sun X, Bi Y, Nong B, Hu D, Sun X, Chen H, et al. Linked color imaging confers benefits in profiling H. pylori infection in the stomach. Endosc Int Open. 2019 Jul;7(7):E885-92.

7 Ono S, Kato M, Tsuda M, Miyamoto S, Abiko S, Shimizu Y, et al. Lavender color in linked color imaging enables noninvasive detection of gastric intestinal metaplasia. Digestion. 2018;98(4):222-30.

8 Sun X, Dong T, Bi Y, Min M, Shen W, Xu Y, et al. Linked color imaging application for improving the endoscopic diagnosis accuracy: a pilot study. Sci Rep. 2016 Sep;6(1):33473.

9 Fukuda H, Miura Y, Hayashi Y, Takezawa T, Ino Y, Okada M, et al. Linked color imaging technology facilitates early detection of flat gastric cancers. Clin J Gastroenterol. 2015 Dec;8(6):385-9.

10 Ono S, Abiko S, Kato M. Linked color imaging enhances gastric cancer in gastric intestinal metaplasia. Dig Endosc. 2017 Mar;29(2):230-1.

11 Kanzaki H, Takenaka R, Kawahara Y, Kawai D, Obayashi Y, Baba Y, et al. Linked color imaging (LCI), a novel image-enhanced endoscopy technology, emphasizes the color of early gastric cancer. Endosc Int Open. 2017 Oct;5(10):E1005-13.

12 Yoshifuku Y, Sanomura Y, Oka S, Kurihara M, Mizumoto T, Miwata T, et al. Evaluation of the visibility of early gastric cancer using linked color imaging and blue laser imaging. BMC Gastroenterol. 2017 Dec;17(1):150.

13 Fukuda H, Miura Y, Osawa H, Takezawa T, Ino Y, Okada M, et al. Linked color imaging can enhance recognition of early gastric cancer by high color contrast to surrounding gastric intestinal metaplasia. J Gastroenterol. 2019 May;54(5):396-406.

14 Kitagawa Y, Suzuki T, Hara T, Nankinzan R, Takashiro H, Sugita O, et al. Linked color imaging improves the endoscopic visibility of gastric mucosal cancers. Endosc Int Open. 2019 Feb;7(2):E164-70.

15 Fujiyoshi T, Miyahara R, Funasaka K, Furukawa K, Sawada T, Maeda K, et al. Utility of linked color imaging for endoscopic diagnosis of early gastric cancer. World J Gastroenterol. 2019 Mar;25(10):1248-58. 


\section{Case Reports in Gastroenterology}

\begin{tabular}{l|l}
\hline Case Rep Gastroenterol 2019;13:532-538 \\
\hline DOI: 10.1159/000504957 & $\begin{array}{l}\text { @ } 2019 \text { The Author(s). Published by S. Karger AG, Basel } \\
\text { www.karger.com/crg }\end{array}$
\end{tabular}
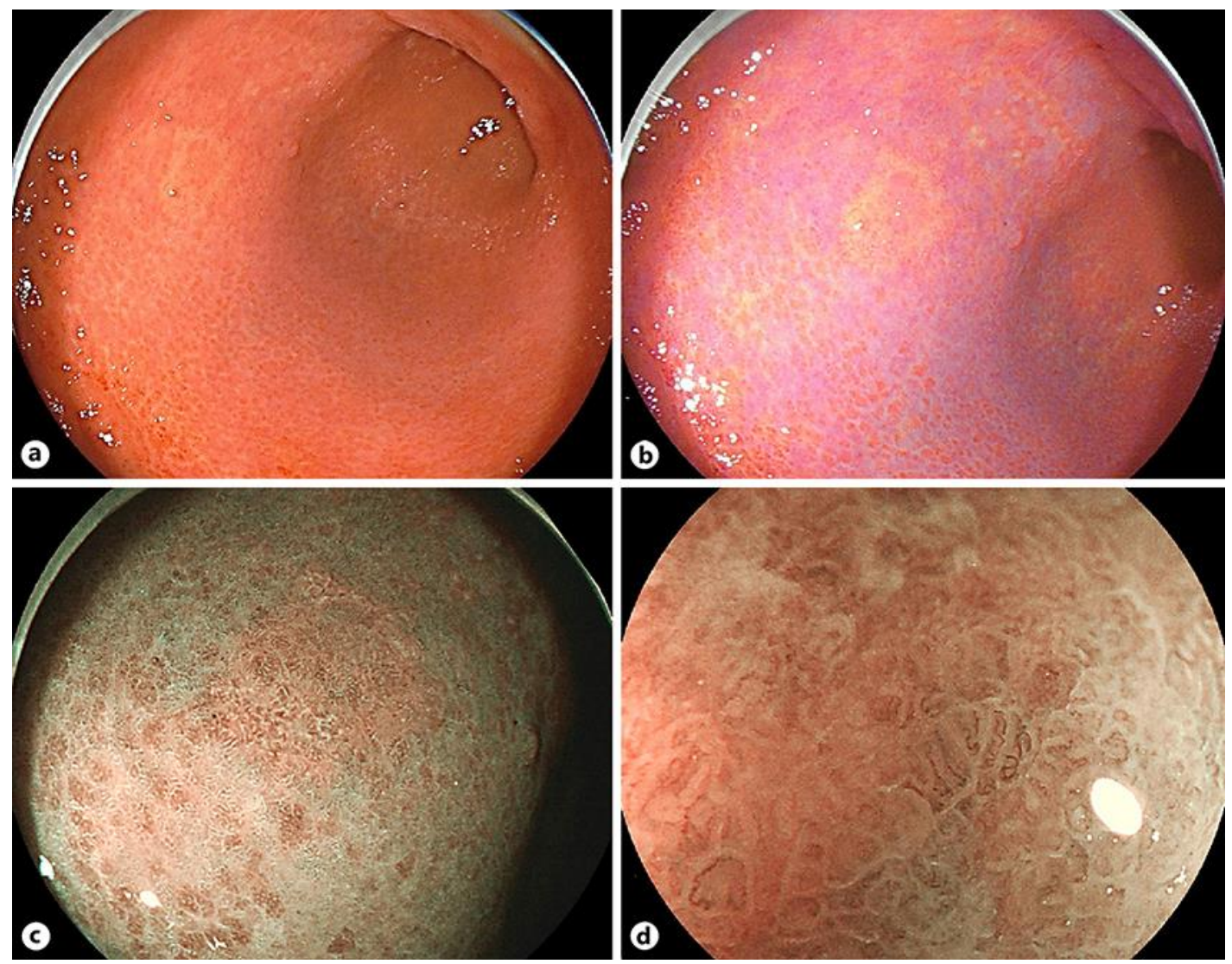

Fig. 1. Esophagogastroduodenoscopy. A yellowish, flat lesion with reddish central area, located in the anterior wall of the gastric lower body shown on WLI (a). On LCI, the lesion was highlighted as an orangish, flat lesion shown to be purple-colored in its central area, surrounded by lavender-colored tissue (b). On BLI, the lesion was depicted as a brownish, well-circumscribed flat lesion (c). An irregular microvascular pattern was shown to be present within the demarcation line on magnifying BLI (d). 


\section{Case Reports in Gastroenterology}

Case Rep Gastroenterol 2019;13:532-538

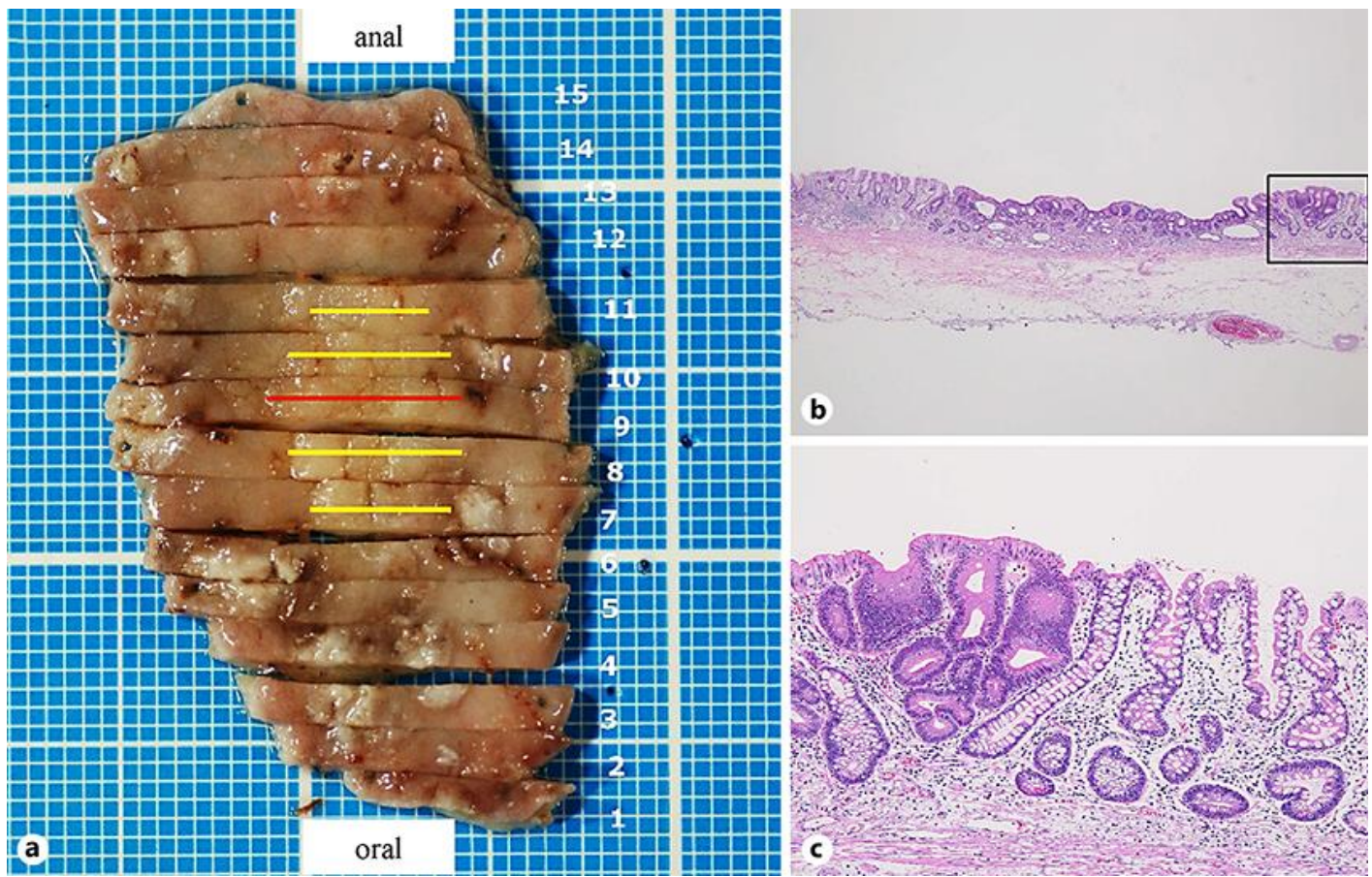

Fig. 2. Macroscopic view of the resected specimen. A 0-IIb adenocarcinoma (tub1) measuring $7 \times 5 \mathrm{~mm}$ was shown to be present in sections 7-11 (a). A histopathologic examination showed the lesion to be welldifferentiated type (tub1) tubular adenocarcinoma (b) surrounded by intestinal metaplasia (c) in section 9.
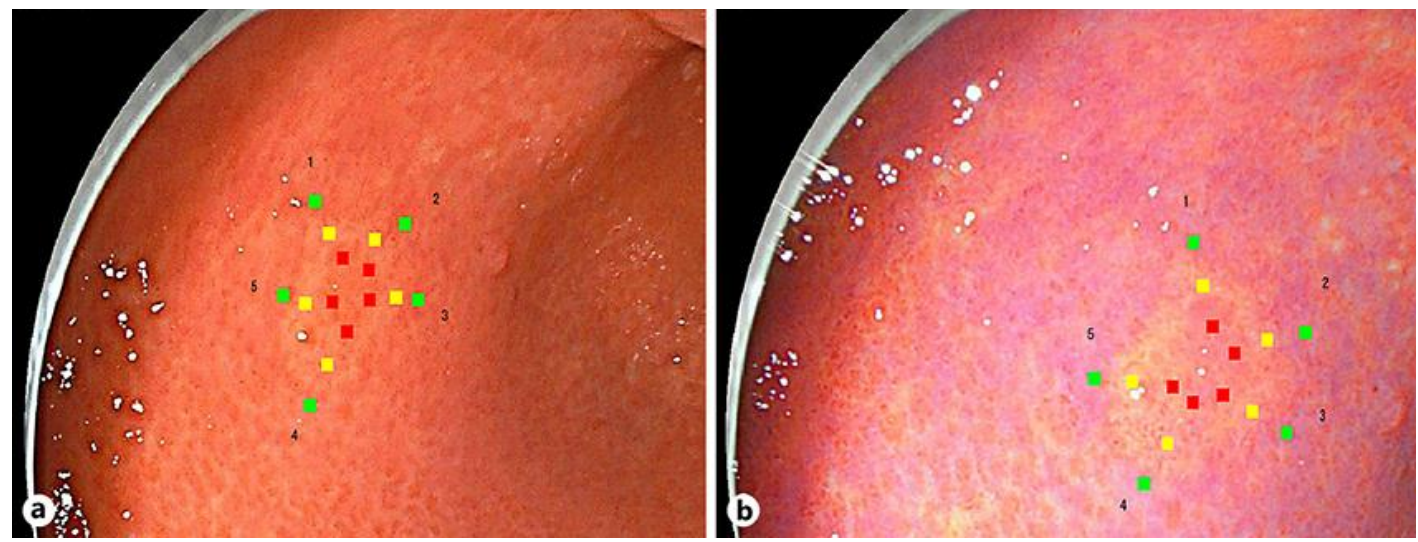

Fig. 3. Calculation of the color difference using the CIE $1976 \mathrm{~L}^{*} \mathrm{a}^{*} \mathrm{~b}^{*}$ color space. Five sampling points were selected from the redness part of the lesion (red squares), the discolored part of the lesion (yellow squares), and the surrounding mucosa (green squares) on WLI (a) and LCI (b), respectively. 
Table 1. Comparison of color differences between WLI and LCI

\begin{tabular}{llll}
\hline & WLI & LCI & $p$ value \\
\hline$\Delta$ E between yellow and green, median (SD) & $8.6(2.5)$ & $17.5(4.4)$ & $0.007^{*}$ \\
$\Delta$ E between red and green, median (SD) & $6.8(3.0)$ & $10.3(4.6)$ & $0.235^{*}$ \\
\hline
\end{tabular}

$\Delta \mathrm{E}$, color difference; green, surrounding mucosa; red, redness part of the lesion; yellow, discolored part of the lesion; LCI, linked color imaging; SD, standard deviation; WLI, white light imaging. * Unpaired $t$ test. 